\title{
Situación actual de los bosques de Chihuahua
}

\author{
Abraham Escárpita Herrera ${ }^{1}$
}

\begin{abstract}
RESUMEN
Los bosques de pino del estado de Chihuahua han sido sometidos a la explotación de madera desde hace un buen número de años, sin que se haya utilizado un buen programa de aprovechamiento. La extracción ha sido intensiva dando importancia únicamente a la madera y dejando de lado los demás servicios que pueden ser aprovechados. Ha existido también una separación entre los objetivos de los poseedores del bosque y los dueños de las industrias, sin que se hayan hecho intentos por plantear estrategias que les permitan a los productores lograr mayores beneficios y a la industria lograr un abastecimiento constante de material de buena calidad sin degradar el capital de los bosques. La realización de los inventarios en los últimos 40 años no refleja exactamente la situación de los bosques ni los volúmenes de madera que pueden ser aprovechados. Los datos publicados no coinciden con la realidad, por lo que no se pueden considerar muy confiables cuando se diseñan los programas de aprovechamiento. Es necesario también diseñar estrategias para la recuperación de los bosques deforestados, mediante la siembra de individuos, partiendo desde la colecta y germinación de semillas y restringiendo por parte las autoridades la apertura de más terrenos forestales para ser convertidos en campos de cultivo agrícola. Por último, es altamente recomendable que se instauren programas de uso múltiple en los bosques para que estos no sean vistos únicamente como proveedores de madera con un lapso de productividad corto, sino que se conserven y manejen de forma integral para abastecer de servicios ambientales no sólo al estado de Chihuahua sino a las entidades vecinas.
\end{abstract}

PALABRAS CLAVE:

Bosque de coníferas, Chihuahua, deforestación, manejo, inventarios forestales, uso múltiple del bosque.

\begin{abstract}
The pine forests of the state of Chihuahua have been submitted to intensive harvesting for a number of years, without the benefit of a good management program. In the process, only the lumber has been considered important and no attention has been paid to the other services that the forest can provide. There has also been a separation between the interests of the forest owners and those of the forest products manufacturers, and no real attempts have been made to implement strategies that while permitting an increase in the forest productivity, can guarantee that the industry obtains constant supplies of quality raw materials without unduly degrading the forest resources. The forest inventories generated in the past 40 years do not reflect the exact situation of the forests neither the volumes that can be adequately extracted. The data published do not coincide with the real conditions of the forest and therefore, can not be trusted as reliable indicators to develop management programs. It is also necessary to design strategies to recover the deforested areas through the plantation of individual trees, starting from the collection and germination of seeds, while restricting the conversion of forest areas into agricultural land. Finally, it is highly desirable that programs of multiple-use of the forests be put into practice, so these can be seen not only as lumber producers with a short-time usefulness, but as providers of multiple environmental services not just for Chihuahua but for the neighboring states.
\end{abstract}

KEYWORDS:

Conifer forests, Chihuahua, deforestation, management, forest inventories, multiple use of the forest. 


\section{INTRODUCCIÓN}

Por primera vez en la historia forestal de México, en los últimos años, el Estado de Chihuahua ha perdido su categoría de líder como productor de maderas y está sufriendo importante rezago en el área industrial, independientemente de un severo deterioro de sus bosques y demás recursos asociados como son los pastos, el agua, la fauna y los suelos que los sustentan. Es bien sabido que los recursos naturales del mundo (agua, bosques, tierra, fauna, petróleo, recursos marinos, etc.) existen, no sólo para su contemplación, sino para cubrir las necesidades de la humanidad; funcionando como satisfactores diversos, cuyo conjunto ha permitido el desarrollo de las civilizaciones desde que la vida apareció en la Tierra. A través del tiempo, el hombre ha conocido y estudiado estos recursos y ha utilizado de ellos lo que necesita para su desenvolvimiento físico, social, económico y cultural. Ha creado formas y procedimientos y, en coordinación con la naturaleza, ha sabido mejorar con lo que originalmente se contaba. Pero también ha sabido destruir... y sigue destruyendo.

La población mundial, en su incesante crecimiento, exige, busca, encuentra y desequilibra. Existe de hecho, una carrera en la cual compiten la capacidad creativa y productiva del hombre, contra su potencia destructiva. Crear no es fácil y lleva tiempo... a veces demasiado; destruir, es inmediato, no es difícil, produce daños, muchos de ellos, irreversibles. Siendo el bosque un recurso natural renovable, tiene, tan sólo por ese hecho, una importancia quizá superior a la del petróleo, el cual, siendo también un recurso natural, tiene un limite que será más cercano mientras más se le consuma. Para entonces, los bosques seguirán produciendo y otorgando los beneficios que se sepan y se puedan obtener de ellos.

Como recurso viviente que es, está indefectiblemente sujeto a las leyes naturales de la vida: nacer, crecer, reproducirse y morir, además requiere para su mejor utilización, de un cultivo apropiado a sus características muy particulares. Los cultivos agrícolas, como el maíz, trigo, avena, frijol, alfalfa y demás, en general, que en unos cuantos meses pueden ser manejados por el hombre y dar productos que le son útiles, ya sea como alimento para consumo o como forraje. Si en el manejo de estos cultivos se cometiese un error, éste puede ser corregido en la temporada siguiente. Los efectos de la fertilización son inmediatos para el año en que se apliquen. Algunos trabajos de mejoramiento de semillas, dan resultados sorprendentes en unos cuantos años. En contraste, los bosques tienen ciclos de vida de tal magnitud, que un error cometido en su uso o manejo, no alcanza una vida para repararlo. Muchos bosques de México están cubiertos por arbolado con edades que fluctúan entre 200 y 300 años y es posible encontrarlos aún más viejos, principalmente en estados como el de Chihuahua, que se caracteriza por tener suelos delgados y pedregosos y una precipitación pluvial no muy generosa, amén de una estación invernal que materialmente suspende por largo tiempo el crecimiento de los árboles.

Erich W. Zimmerman, en su libro "Recursos e Industrias del Mundo" (1957), expresa en relación con los problemas de los bosques: "Amenazas de agotamiento. En los tiempos actuales, la mayor parte de los bosques son explotados de tal forma, con abuso y abandono, que los expertos pronostican tremendas calamidades para un futuro no remoto y daños irreparables de carácter catastrófico. Estos expertos ponen énfasis en su afirmación que, por fin, los hombres son dueños hoy de los conocimientos necesarios para transformar los bosques en tesoros perpetuos, $y$ en que, si no aplican sus conocimientos, explotándolos razonablemente y sobre la base de rendimientos permanentes, una de las mayores fuentes de posibles recursos de que dispone el hombre se perderá pronto sin esperanzas de posible renovación $y$ se convertirá en una verdadera amenaza". El mismo autor menciona también: "¿Por qué aparece el hombre decidido a destruir uno de los 
mayores dones de la naturaleza? Hasta no hace mucho la respuesta a esta pregunta podía resumirse en una sola palabra: ignorancia".

Meditando sobre estos conceptos de Zimmerman (1957), no se puede menos que darle toda la razón cuando nos damos cuenta y hemos estudiado que en aquellos países de añeja tradición forestal, como son los países escandinavos de Suecia, Finlandia, Noruega, así como Alemania y Francia por mencionar algunos, sus bosques que han sido trabajados durante generaciones enteras, siguen conservando sus mismas características de superficie, volúmenes, crecimiento y sanidad $\mathrm{y}$, en muchos casos, éstas han sido mejoradas. Se trata de países donde su población tiene una dependencia económica muy directa e importante de tales recursos, los cuales reciben un esmeradísimo cuidado por parte de sus dueños en contra de incendios, plagas y cualquier otro factor destructivo. Los trabajos de plantaciones forestales en estos países, cuando forman parte de algún programa de manejo o de recuperación de suelos, son de extraordinaria calidad y precisión. Son países con tecnologías de punta que inclusive, son motivo de exportación. Complementariamente, se trata de países con una población estable en donde las tasas de natalidad y mortalidad son prácticamente iguales por lo que, no se tienen presiones destructivas sobre los recursos naturales a fin de satisfacer las demandas de una población que está creciendo constantemente.

A este respecto, es interesante mencionar que algunos estudios señalan que en los años en que nació Jesucristo, la población del mundo era de alrededor de 250 - 300 millones de habitantes. Para el año 1650, esta población se había duplicado o sea, ya se tenían entre 500 y 700 millones. En los siguientes 200 años, para 1850, se duplicó de nuevo, volviendo a duplicarse para 1950, o sea, a la vuelta de solamente 100 años. Actualmente se habla de alrededor de 6000 millones de seres humanos que no solamente requieren de alimentos sino que destruyen y contaminan las fuentes de producción.

En el caso específico de México, INEGI señala para 1970 una población de 48 millones de habitantes y para 1991 de 81 millones. Esto es, un crecimiento en solamente 20 años de 35 millones que representan el $68 \%$ de la población de 1970, cuyo incremento anual para ese período fue de $3.4 \%$. Actualmente se considera una población de alrededor de 100 millones de personas que es más del doble de la que había hace apenas 30 años. Este incesante crecimiento requiere de medios de subsistencia en todos los órdenes y son justamente los recursos forestales, entre otros, los que están sufriendo una terrible presión que se manifiesta por medio de una sobreexplotación, incendios, cambio desordenado de uso del suelo, erosión, agotamiento de mantos acuíferos, contaminación de ríos y atmosférica, degradación ecológica, etc.

No es admisible que en la actualidad se siga usando el fuego dentro del bosque en forma indiscriminada como elemento para eliminar árboles, matorrales y para limpiar tierras para dedicarlas a una agricultura pasajera de tal vez no más de dos o tres años. Terrenos que posteriormente son abandonados a merced de la erosión.

\section{ANTECEDENTES}

El estado de Chihuahua es el de mayor extensión territorial en México y el que contiene la mayor superficie forestal y arbolada. Sus bosques están integrados por diversas especies de pino y un porcentaje moderado de encinos. Adicionalmente se tiene un sotobosque formado por arbustos de pequeña talla, formando todos ellos una bella composición florística que le ha dado fama a este estado, principalmente cuando se asocian a la famosa Barranca del Cobre y las no menos espectaculares cascadas de Basaseachi y de Cusarare. Todo este conjunto de especies de armónica belleza que cubren los 5.1 millones de hectáreas de 
bosques en el estado de Chihuahua, tienen, además, una gran importancia económica y social, no solamente para este estado, sino para el país en su conjunto, como resultado del abastecimiento de sus productos forestales a industrias de otros estados. Es importante mencionar que de los 5.1 millones de hectáreas que cubren los bosques de Chihuahua, el $65 \%$ en números redondos, son de propiedad ejidal, cuyos poseedores viven dentro de ellos o en sus proximidades (Juárez y Pando, 1993).

Cuando, la población rural, que por razones étnicas, siempre había vivido dentro de los bosques, fue favorecida con la disposición oficial de pasar a ser propietaria de dichos recursos dejando de ser solamente trabajadores de las industrias a las que originalmente abastecía, se produjo una conmoción nacional que trastocó toda la actividad forestal. Se formaron ejidos forestales por doquier por lo que, cada ejido debería contar con autoridades que se hicieran cargo de su administración, para la cual no estaban preparados, iniciándose un cambio brutal tanto en la administración, como en el manejo y la comercialización de los bosques que les habían sido dotados, así como también, en la mentalidad de la gente del bosque.

Muchos ejidos se convirtieron en simples vendedores de materias primas a las industrias que ya estaban trabajando y algunos otros intentaron probar fortuna como industriales directos y participar en el mercado de productos aserrados, que era lo máximo a lo que podían aspirar, toda vez que carecían de recursos financieros para aspirar a industrias de mayor valor agregado, independientemente de que desconocían, como administradores, lo relativo a maquinaria, mercados, sistemas de distribución y principalmente a los asuntos financieros necesarios en cualquier negocio.

La decisión del gobierno federal de realizar la dotación ejidal de los terrenos forestales, fue tan inesperada desafortunadamente, que no se tuvo la precaución de diseñar algún mecanismo que estableciera criterios de igualdad en dicho reparto. Fue así, que se crearon ejidos muy ricos y otros muy pobres de acuerdo con el número de solicitantes y con los volúmenes de corta posibles en cada caso. En ciertos ejidos, el bosque es tan extenso y productivo, que a cada miembro ejidal les ha venido tocando más de $200 \mathrm{~m}^{3}$ por año como volumen de corta, ya sea para su venta directa o para su industrialización, lo que les deja ingresos importantes, mientras que otros, llegan a comercializar escasamente 1 ó $2 \mathrm{~m}^{3}$ por ejidatario.

El resultado inmediato de esta desigualdad ha propiciado una explotación muy intensa y destructiva de los bosques ejidales menos favorecidos, como una manera de satisfacer sus necesidades mínimas de supervivencia e inclusive ha creado una invitación hacia el uso de sus tierras para el cultivo de enervantes, prácticas por demás conocidas por todo el mundo, además de su alta rentabilidad que supera con creces al rendimiento del cultivo de sus bosques. De ahí su desinterés por manejar y conservar la productividad de estos. Si a lo anterior se aúna el incremento incesante de la población, en un futuro no muy lejano, a cada miembro ejidal le corresponderán menos beneficios, vislumbrándose cada vez una mayor presión sobre lo que va quedando de los bosques originales.

Es igualmente importante citar el hecho de que cuando se llevó a cabo el reparto agrario de los bosques, quedó establecido un gran problema, no solamente en el estado de Chihuahua, sino en todo el país; que consiste en que los nuevos propietarios carecían, y a la fecha muchos de ellos aún carecen, de industrias de transformación además que las industrias carecen de bosques que sean de su propiedad. Por ello y en función de criterios discordantes de comercialización, con mucha frecuencia si no es que en forma permanente, la industria padece de un abastecimiento seguro. Por su parte, los dueños de los bosques no encuentran a quien vender en las condiciones de precio establecidas por ellos. Es notorio además, que este negocio no se maneja en función 
de la oferta y la demanda, toda vez que los precios de la madera que se corta siempre están en constante aumento quedando al alcance del mercado internacional, pues a la fecha no se ha visto que cuando el mercado es deficitario los precios tiendan a disminuir. Es así como una gran riqueza forestal no tiene un significado realmente importante en la solución de los problemas económicos de sus poseedores.

Aquí cabría un cuestionamiento que de resolverse, pudiera ayudar a solucionar muchísimos problemas: ¿Por qué, si la ley lo permite, no se forman sociedades en la que participen los dueños y poseedores de bosques con los dueños de las industrias? Cada parte aportaría sus recursos y se establecerían dividendos en función del valor real de dichas partes. Este mecanismo aseguraría un abastecimiento permanente a la industria y a los dueños de bosques una venta segura con ingresos anuales también permanentes. En esta forma, la responsabilidad de cuidar y mantener los bosques permanentemente productivos, así como proporcionarles la protección necesaria contra elementos nefastos como el fuego, plagas y sobre todo cortas ilegales, ya no sería solamente de sus dueños sino también de la organización industrial.

En el mismo sentido y en forma adicional se debe mencionar que la Sierra Madre Occidental, que cruza el estado de Norte a Sur a lo largo de aproximadamente $850 \mathrm{~km}$, capta una precipitación pluvial que otorga a Chihuahua un papel protagónico como el abastecedor de agua más importante para los estados de Sinaloa y Sonora, principalmente el primero, a los que permite ser los mejores productores de hortalizas del país. El agua que escurre para estos estados es recibida y controlada en las áreas arboladas de Chihuahua, así como también la que vierte para la cuenca del Golfo de México a través del Río Conchos, irrigando extensas áreas agrícolas en la región de Ciudad Delicias y Ojinaga.

A fin de dar una somera idea numérica de estos volúmenes de agua y suponiendo una precipitación pluvial anual promedio de tan solo $600 \mathrm{~mm}$, con referencia solamente a los 5.1 millones de hectáreas de bosques, se tiene un total de $30600 \times 10^{6} \mathrm{~m}^{3}$ de agua. Descontando la evaporación y los volúmenes que se infiltran en el suelo, se considerarían los escurrimientos en un $10 \%$, correspondiendo a $3060 \times 10^{6} \mathrm{~m}^{3}$. El agua captada, después de largos recorridos, se almacena en diferentes presas construidas para tal fin, principalmente en el estado de Sinaloa. Suponiendo, nuevamente, que para satisfacer las necesidades de riego de un cultivo agrícola se requiere una capa de agua (tirante) de $50 \mathrm{~cm}$ en su ciclo completo (distribuidos en varios riegos), es posible regar una superficie de alrededor de 600000 ha o su equivalente de 300000 ha, con dos cultivos al año.

Aquellos agricultores propietarios de terrenos en los diferentes distritos de riego, deben pagar por el volumen de agua que se les otorga, costo que incluye no solamente el valor del agua, sino también toda la urbanización y administración hidráulica: canales, caminos, personal, etc. Los ingresos que se captan van directamente al Gobierno Federal, pero éste no reintegra un sólo centavo al gobierno de Chihuahua para que los utilice en programas para cuidado y conservación de sus bosques con el fin de mantenerlos permanentemente productivos, ya sea previniendo o minimizando los incendios forestales, evitando los procesos erosivos y reduciendo al mínimo la contaminación de ríos y arroyos. Por el contrario, tal responsabilidad se les deja por entero a los dueños, quienes obviamente, carecen de los recursos económicos para este fin, dando lugar al desarrollo del grave problema del descuido y abandono de los bosques de Chihuahua. Si a los distritos de riego se les aprueban presupuestos importantes para caminos, administración, mantenimiento de canales, y otros rubros ¿Por qué no asignar otro igualmente importante al recurso forestal? que es por decirlo de alguna manera, el elemento más importante en la producción de agua. Lo anterior sin embargo, deja constancia bien definida de un valor adicional de 
extraordinaria importancia ligado de forma indisoluble al recurso forestal.

Otros recursos que producen bienes y servicios derivados de los bosques en forma directa, son los relativos a la fauna silvestre, los pastos y los muy importantes de la recreación y el ecoturismo. Con respecto a este último se ha sabido, a través de notas periodísticas, de grandes proyectos por llevarse a cabo en las inmediaciones de la famosa Barranca del Cobre, adicionales a las que ya están en operación en el poblado de Creel, en donde es de notarse una permanente corriente de visitantes. Quienes vienen a estas áreas, son atraídos sin duda, por la belleza escénica y extraordinaria topografía de sus bosques, sus veredas, la pureza de sus aires así como los aspectos culturales de sus habitantes.

Se entiende por lo mismo, que lo que se está vendiendo es el escenario en el cual el bosque es el primer actor. Sin embargo, nuevamente el propietario de dicho escenario o al menos en los ejemplos que se tienen actualmente, no recibe retribución alguna o participación de los ingresos que se recaudan los cuales sin duda son de importante cuantía. Si se lograra que los dueños o poseedores recibieran alguna participación por este concepto, se aplicaría solamente en aquellas áreas que se seleccionaran para propósitos turísticos y, que por lo mismo, no estén sujetos a trabajos de aprovechamiento forestal, ya que a nadie le agradaría un escenario con bosques residuales, con un número escaso de árboles tal vez raquíticos $y / 0$ mal conformados como residuos de una explotación, además de los desperdicios propios de la misma explotación. De cualquier manera, se vuelve a presentar el mismo problema que con el agua: no se cuenta con alicientes para los dueños del recurso. No obstante los diversos inconvenientes que se generan al interior de los bosques, no es difícil entender que se trata de un recurso natural capaz de ofrecer innumerables satisfactores y beneficios al hombre con la condición de saberlo manejar siguiendo procedimientos técnicos que ya se conocen, los que son de aplicación exitosa en diversos países. Veamos ahora por qué no se han podido lograr obtener los beneficios que teóricamente es posible obtener de los bosques de Chihuahua.

\section{INVENTARIO FORESTAL 1962}

El cultivo forestal es un cultivo que brinda resultados a muy largo plazo, principalmente en los bosques cubiertos con arbolado de pino, como lo son los del estado de Chihuahua. Su explotación data desde siempre, en una forma que ha sido más intensa en la medida en que la población se ha ido incrementando. Desde principios del siglo pasado y con la construcción del ferrocarril, se realizaron cortas, que más bien se podrían llamar "destrozos" del arbolado para el trazo de las vías y la producción de durmientes, en una forma por demás desordenada e intensa, sin tener una idea del manejo técnico, debido a que en aquella época no se contaba con personal profesional en tales disciplinas. Dadas las grandes extensiones de bosques con que contaba el estado, tales aprovechamientos se realizaron principalmente en las áreas de fácil acceso, quedando la mayor parte sin aprovechar, en estado virgen. De cualquier manera, se causaron graves daños, tanto a los bosques como a los suelos, que aún no se han podido recuperar.

Pasaron muchos años antes de que la tecnología forestal llegara a estos bosques y se pudiera definir con la precisión requerida su tamaño y características para poder diseñar y establecer sistemas que garantizaran un cultivo permanente y el capital bosque siguiera por siempre, ofreciendo un rendimiento igual cada año. Es por ello que para estar en posibilidad de citar antecedentes numéricos y confiables de lo que existía, se tomarán como base las primeras cifras oficiales que se conocen en forma global para todo el país y en particular para los bosques del estado de Chihuahua, las que datan del año 1962, fecha en que se inició, precisamente en 
esta entidad, el primer inventario forestal de México, utilizando para lograrlo la tecnología más moderna de aquel momento en el ámbito mundial.

Por primera vez se usaron fotografías aéreas para clasificar los bosques de acuerdo con sus diferentes características de espesuras y tipos de árboles; se tomaron alrededor de 40000 muestras de campo para medir sus dimensiones y tasa de crecimiento; se pudo conocer con precisión su ubicación geográfica, se manejó, por primera vez también, equipo electrónico de cálculo, medidores de grandes distancias con sistemas de radar, helicópteros y otras de técnicas que hicieron de dicho inventario el punto de partida para un gran avance en el manejo de los bosques del estado. Se citarán entonces, como resultados de aquel primer inventario de 1962, unas cuantas cifras que darán idea de "qué se tuvo" en Chihuahua, como base de comparación para otras cifras posteriores:

\begin{tabular}{lc}
\hline \multicolumn{1}{c}{ Concepto } & $\begin{array}{c}\text { Miles de } \\
\text { hectáreas }\end{array}$ \\
\hline Superficie forestal & 16134 \\
\hline Superficie arbolada & 5100 \\
\hline Superficie de coníferas & 4161 \\
\hline Superficies perturbadas & 700 \\
\hline
\end{tabular}

Un dato por demás importante, es el que se conoce como "capital bosque", que representa el volumen de madera de todas las especies de árboles que conforman dicho bosque, expresado en metros cúbicos. Sin embargo, para el propósito de este análisis se manejara únicamente el volumen reportado para la madera de pino, que es la de mayor importancia comercial y la que mayor presión resiente por parte de la industria, cuyo volumen se determinó en $230524000 \mathrm{~m}^{3}$. Para este capital bosque se encontró un incremento, un rendimiento o un interés anual de $3749500 \mathrm{~m}^{3}$, que equivale al $1.6 \%$, y que representa el volumen que se podía cortar cada año sin detrimento del capital productor.

En bosques vírgenes, en los cuales el incremento no es perceptible debido a la competencia entre individuos y a la escasez de nutrientes en el suelo que ya no puede seguir alimentando más árboles, se requiere que se corten algunos árboles para ser comercializados o que sean suprimidos de forma natural dejando lugar a individuos nuevos que los sustituyan. Cuando en este tipo de bosques se inicia un proceso de aprovechamiento técnicamente diseñado y se hace necesario cortar, por lo general, los árboles más viejos, el incremento de los árboles residuales, al contar con mayor espacio vital, tenderá a aumentar y la producción posterior, será mayor.

Tomando como base las primeras cifras que se estimaron para los bosques de Chihuahua -superficies y volúmenes- es ilustrativo ahora, después de 29 años, analizar los mismos conceptos calculados por otro inventario forestal nacional que también incluyó a la entidad adicionando información sobre la dinámica de los aprovechamientos a lo largo de los años que se indican. La razón de agregar esta última información sobre volúmenes autorizados y volúmenes cortados, se debe a que existe un estrecho paralelismo entre ellos y la calidad de los bosques residuales.

\section{INVENTARIOS 1990}

Siendo los bosques un recurso natural viviente, dinámico, sensible a acciones excesivas que alteran su fisiología y siendo el hombre un elemento que tiende a desestabilizarlo por los aprovechamientos que no toman en cuenta tales características, es totalmente posible que los resultados negativos se presenten en relativamente poco tiempo. Los bosques son la base de la economía de muchos países en el mundo y también en el nuestro, en virtud de sus extensiones y variabilidad ecológica (bosques tropicales y bosques de clima frío y templado) y que por lo tanto, de su manejo adecuado dependen diversos 
recursos asociados que también tienen una importancia económica cuantiosa.

El bosque no es sólo madera; también es agua, es recreación, es fauna, ganadería y sobre todo es ecología y el manejo de todos ellos, forman una formidable fuente de ingresos que como todos los negocios se deben conocer profundamente para saber y poder manejarlo con resultados positivos. Es preciso definir sus características cualitativas y cuantitativas, los principios técnicos que lo gobiernan, su respuesta ante intervenciones humanas, el entorno social que lo rodea, sus características económicas, factores negativos que lo agreden, entre otros.

En el caso de los recursos forestales, cuya utilización en nuestro país está subordinada a la Administración Pública Federal, a través de leyes y reglamentos específicos, tomando en cuenta, además, que la dinámica a que están sometidos - ya sea la suya propia o la que le impone el hombre mediante su aprovechamiento - se obliga el seguimiento permanente de las principales características que se usan para su identificación: distribución territorial, extensiones, volúmenes, incrementos, distribución diamétrica, composición botánica, etc.; esta información, si es manejada de manera adecuada por las autoridades correspondientes puede en un momento dado evitar desequilibrios ecológicos difíciles de remediar en el corto tiempo.

Es por ello que el mejor instrumento para establecer dicho seguimiento, son los inventarios forestales, los cuales, para una administración estatal o nacional, tienen características específicas y diferentes a las de los inventarios de manejo forestal. Un inventario forestal es la mejor herramienta de la que disponen las autoridades para dirigir exitosamente el uso de sus bosques. Es por esto que la Ley Forestal (1997) expresa en su artículo $5^{\circ}$ Fracción I, que son atribuciones de la SEMARNAT en materia forestal: "realizar y mantener actualizado el inventario forestal nacional".
Muchos países que dependen en forma importante de la derrama económica de sus bosques, realizan inventarios forestales a escala nacional o estatal, con una frecuencia de 10 años, que se pueden integrar con trabajos anuales; esto es, cada año efectúan muestreos equivalentes a una décima parte del total y a los 10 años determinan resultados para el período. Sin embargo, cada año van monitoreando el curso de los aprovechamientos. Con dicha información, la anual o la del período de 10 años, ajustan sus políticas sobre el uso y aprovechamiento de los bosques. Se toman decisiones, para aumentar o disminuir los volúmenes de corta anual; cambiar y seleccionar el uso que proporcionen los mejores resultados económicos y/o sociales, ya sea como simples productores de madera o para recreación o mantenerlos exclusivamente como productores de agua o hábitat de fauna, por ejemplo.

Como ya se mencionó, el primer inventario forestal para el estado de Chihuahua se llevó a cabo en el año de 1962. Por diversas razones, principalmente políticas, un segundo inventario se realizó 29 años después, entre 1991 y 1992. Durante este lapso no hubo ninguna señal de cambio en las políticas oficiales responsables de los bosques; por el contrario, hubo una indiferencia absoluta hacia este renglón por parte de las autoridades correspondientes. Por ejemplo tan sólo en el período de 1978 a 1999 se designaron 13 subsecretarios forestales, es decir un promedio de un subsecretario cada 1.6 años. Como se ve, se trata de una dependencia oficial que sirve sobre todo como un escalón político que muestra una absoluta indiferencia hacia un recurso de la importancia y magnitud que son los bosques.

La información oficial del segundo inventario nacional, que se dio a conocer como "Inventario Nacional Forestal de gran Visión" menciona: "En la elaboración del mapa forestal se utilizaron técnicas avanzadas de percepción remota, 
mediante el uso de imágenes de satélites de diferentes tipos. Uno de estos corresponde a las imágenes de satélite NOAA para observaciones meteorológicas, cuya aplicación a gran escala es una innovación en nuestro país. Para afinar la información cartográfica se emplearon imágenes LANDSAT TM de alta resolución". "Los análisis de cambios ocurridos en la vegetación forestal por deforestación y degradación son un elemento nuevo, que se incorpora para comprender mejor la dinámica de este importante recurso y emprender las acciones necesarias para su conservación y fomento".

Tratando entonces de definir algunos cambios en los elementos ya mencionados y expresados anteriormente y que son comparables entre sí, se tienen los siguientes resultados:

\begin{tabular}{|c|c|c|}
\hline \multirow{2}{*}{ Concepto } & \multicolumn{2}{|c|}{$\begin{array}{c}\text { Inventarios } \\
\text { (miles de hectáreas) }\end{array}$} \\
\hline & 1962 & 1991-92 \\
\hline $\begin{array}{l}\text { Superficie } \\
\text { forestal }\end{array}$ & 16134 & 15553 \\
\hline $\begin{array}{l}\text { Superficie } \\
\text { arbolada }\end{array}$ & 5100 & 4949 \\
\hline $\begin{array}{l}\text { Superficie de } \\
\text { coníferas }\end{array}$ & 4161 & 4027 \\
\hline $\begin{array}{l}\text { Superficies } \\
\text { perturbadas }\end{array}$ & 700 & 976 \\
\hline $\begin{array}{l}\text { Volumen de } \\
\text { coníferas }\left(\mathrm{m}^{3}\right)\end{array}$ & 230524000 & 241650960 \\
\hline $\begin{array}{l}\text { Incremento } \\
\text { anual }\left(\mathrm{m}^{3}\right)\end{array}$ & 3749500 & 3624764 \\
\hline
\end{tabular}

Un primer análisis de estos resultados permite ver diferencias importantes en los valores de las superficies, las cuales son inferiores en los años 91-92. Se nota que la superficie de coníferas es menor en 134000 ha pero que, sin embargo, los volúmenes de pino correspondientes a esas superficies son mayores en $1112696 \mathrm{~m}^{3}$, mientras que los incrementos son menores. Cómo es posible entonces, que habiéndose reducido la superficie, aumentara el volumen (capital bosque) y disminuyera el incremento (interés)?

Posteriormente y en forma sorpresiva por lo inmediato de su realización, en los años 1992-94, fue publicado por la Subsecretaría de Agricultura y Recursos Hidráulicos, el Inventario Nacional Forestal Periódico 1992-1994 (SARH, 1994).

En el capítulo de Antecedentes del documento se asienta: "La falta de una evaluación continua periódica de los recursos forestales del país, no ha permitido conocer con precisión cuáles han sido los cambios en el recurso forestal, en dónde han ocurrido y por qué causas, de manera que pudieran instrumentarse acciones que permitieran disminuir la degradación y deforestación de la Nación". "La Subsecretaría Forestal y de Fauna Silvestre actualizó en 1991 el primer inventario nacional forestal a través del Inventario Nacional Forestal de Gran Visión, con el cual se plasmaron las áreas forestales del país en mapas con escala 1:1 000 000." "Para precisar los datos del mismo, se tomó la importante decisión de realizar una evaluación más detallada, que debía actualizarse periódicamente cada 10 años, dando lugar al "Inventario Nacional Forestal Periódico" iniciado en 1992. Después de exhaustivas investigaciones se decidió que su elaboración se haría a partir de imágenes TM de alta resolución del satélite LANDSAT, y que las cartas forestales del país se presentarían en escala 1:250 000..."

Lo anterior explicaría que el inventario de 1991-92, se llevó a cabo para actualizar el de 1962 y que el de 1992-94, para precisar los datos del de 1991-92. Fue así que se tuvo y aún se tiene, una tercera relación de cifras que lejos de aclarar, confunden a los usuarios de la información ahí presentada, principalmente a las mismas autoridades, que en última instancia son quienes las necesitan. 
A continuación los resultados para este Estado de Chihuahua de los tres inventarios:

\begin{tabular}{|c|c|c|c|}
\hline \multirow{2}{*}{ Concepto } & 1962 & $1991-92$ & $1992-94$ \\
\hline & \multicolumn{3}{|c|}{ miles de hectáreas } \\
\hline $\begin{array}{l}\text { Superficie } \\
\text { forestal }\end{array}$ & 16134 & 15553 & 17528 \\
\hline $\begin{array}{l}\text { Superficie } \\
\text { arbolada }\end{array}$ & 5100 & 4949 & 7592 \\
\hline $\begin{array}{l}\text { Superficie de } \\
\text { coníferas }\end{array}$ & 4161 & 4027 & 4072 \\
\hline \multirow[t]{2}{*}{$\begin{array}{l}\text { Superficies } \\
\text { perturbadas }\end{array}$} & 700 & 976 & 768 \\
\hline & \multicolumn{3}{|c|}{ millones de $\mathrm{m}^{3}$} \\
\hline $\begin{array}{l}\text { Volumen de } \\
\text { coníferas }\end{array}$ & 230 & 241 & 217 \\
\hline
\end{tabular}

Una comparación de los volúmenes anteriores, deja dudas que impiden definir lo que está sucediendo con los bosques del estado, ya que analizando únicamente los valores de las superficies, se puede inferir que lo que se está haciendo en materia de aprovechamientos forestales en Chihuahua es aparentemente positivo, puesto que la superficie forestal aumentó con respecto a 1962 en 1393000 ha esto significa más de 48000 ha/año; la superficie arbolada aumentó en ese mismo período a 2492000 ha para un promedio anual sostenido, durante 29 años, de 85000 ha; y ya en 1991-92 (29 años después), éstas llegaron a 976000 ha, pero dos años más tarde ya sólo fueron 768000 ha.

Reiterando el hecho de que el bosque es un recurso cuyo cultivo requiere de un buen número de años para manifestarse en forma aparente, inclusive a la vista de los expertos, los cambios que expresan los inventarios ya comentados, no dejan de ser totalmente increíbles, ya que, por ejemplo, la superficie arbolada no pudo aumentar 2.6 millones de hectáreas en el intervalo en que se realizaron los dos inventarios más recientes y la superficie forestal también aumentó 1394000 ha en el mismo lapso. Sin embargo, los volúmenes correspondientes a esa superficie forestal en ese mismo periodo disminuyeron 24 millones de metros cúbicos, cifra que representa el volumen de corta de 3 años para toda la República.

La única explicación que se tendría para esta información, es que los responsables de la ejecución de tales trabajos, no manejaron los mismos conceptos ni los mismos términos forestales, calificando por ejemplo, una superficie arbolada como superficie de coníferas o viceversa. Lo más grave sería la presencia de errores ya sea en las mediciones del arbolado en los trabajos de campo, como en los de gabinete en la interpretación y definición de las imágenes del satélite 0 en ambos. De cualquier manera, tales inventarios no ofrecen una base segura para conocer en un momento dado, el curso que sigue el proceso de aprovechamiento de nuestros bosques.

Lo que es innegable, es que el estado de Chihuahua está siendo víctima de una deforestación tan acelerada y destructiva, que no es difícil pronosticar graves desastres en un período de tiempo muy corto. Calculado este período en términos de lo rápido que la población mexicana está creciendo, la que en los próximos 20 años, probablemente se haya duplicado exigiendo satisfactores de diversa índole, incluyendo los derivados del bosque: madera, casas, muebles, papeles, agua no contaminada, etc.

A este respecto, es interesante analizar la trayectoria seguida por los aprovechamientos forestales que se han autorizado en los últimos años en el estado, los cuales resultan alarmantes, difícil de no percibir, en el sentido de que algo anda mal al interior del bosque. Las estadísticas que se anexan y que son oficiales, expresan para los años que se indican, los volúmenes totales autorizados (pino, encino, otros), los volúmenes autorizados solamente para el pino y los que se extrajeron de esa misma especie así como el porcentaje correspondiente (Fig. 1). 


\begin{tabular}{ccccc}
\hline & $\begin{array}{c}\text { Volumen total } \\
\text { autorizado }\end{array}$ & \begin{tabular}{c} 
Volumen \\
autorizado pino \\
\cline { 2 - 4 }
\end{tabular} & $\begin{array}{c}\text { Producción } \\
\text { pino }\end{array}$ & \multirow{2}{*}{$\%$} \\
\hline 1989 & 3505 & 2654 & 1341 & 50.5 \\
\hline 1990 & 3626 & 2655 & 1381 & 52.2 \\
\hline 1991 & 2689 & 1975 & 1175 & 59.5 \\
\hline 1992 & 2485 & 1803 & 1239 & 68.7 \\
\hline 1993 & 2331 & 1641 & 985 & 60.0 \\
\hline 1994 & 2413 & 1807 & 1019 & 56.4 \\
\hline 1995 & 2645 & 1833 & 1188 & 64.8 \\
\hline 1996 & 2815 & 2140 & 1204 & 56.2 \\
\hline 1997 & 2453 & 1869 & 1184 & 63.3 \\
\hline
\end{tabular}

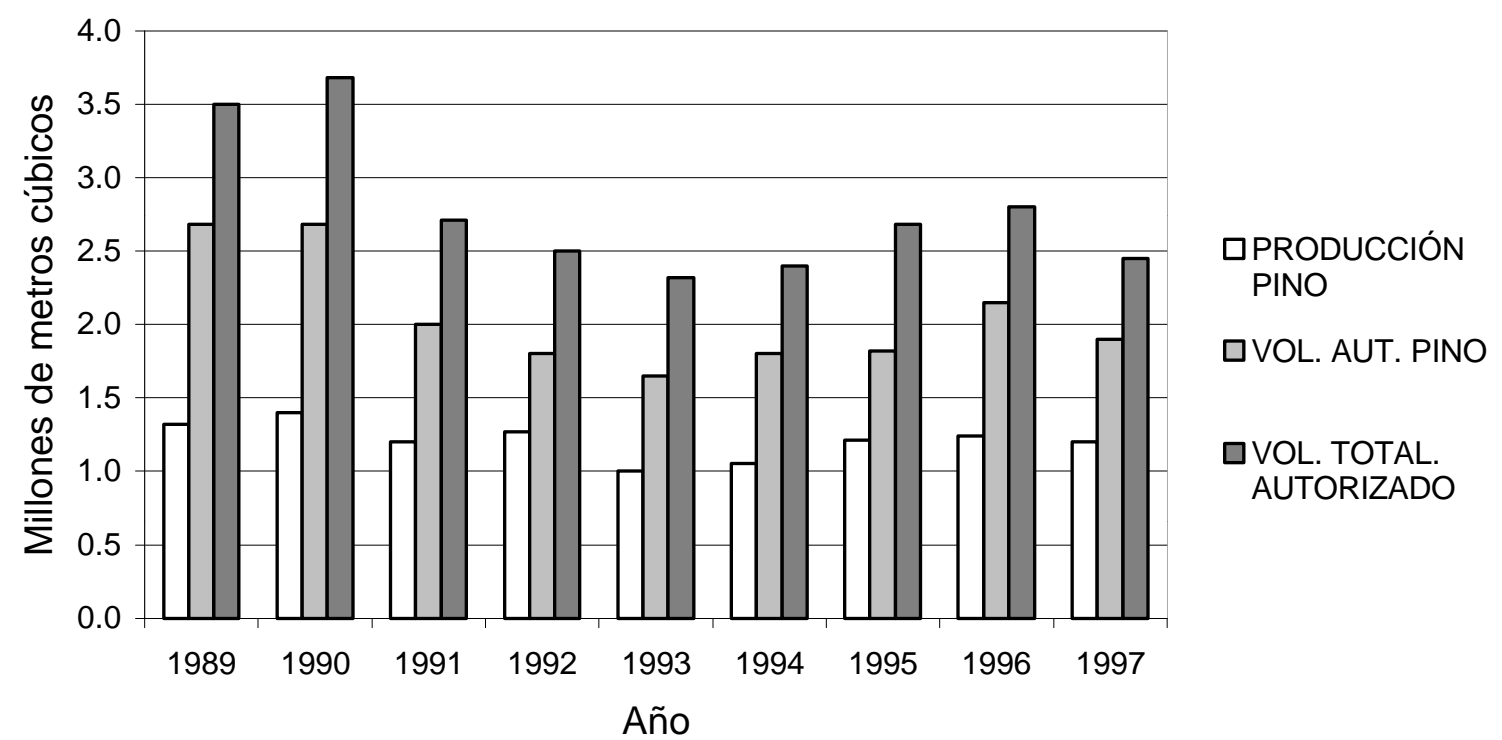

Figura 1. Volúmenes autorizados vs volúmenes de corta.

Manejando solamente los valores promedio para estos 9 años, los volúmenes registrados fueron los siguientes:

\begin{tabular}{lc}
\hline \multicolumn{1}{c}{ Concepto } & miles $\mathrm{m}^{3}$ \\
\hline Volumen total autorizado & 2774 \\
\hline Volumen autorizado de pino & 2042 \\
\hline Volumen producción de pino & 1191 \\
\hline
\end{tabular}

Considerando que la capacidad natural productiva de estos bosques, es del orden de 3.6 millones de metros cúbicos, la interrogante que surge de inmediato es: ¿por qué solamente se produjo en ese período un promedio de $1191000 \mathrm{~m}^{3}$ que representan el $58.3 \%$ de lo autorizado y el $33 \%$ del incremento? Adicionalmente, las estadísticas indican que del arbolado que se cortó en ese mismo período, entre el 40 y el $45 \%$ está integrado por árboles que escasamente tienen un diámetro de entre 
10 y $30 \mathrm{~cm}$, el 55 a $60 \%$ restante lo representan árboles con diámetros de 35 $\mathrm{cm}$ y mayores. Nuevamente cabe preguntar: ¿Por qué tan alto porcentaje de diámetros pequeños? ¿Será que la capacidad productiva del bosque no es suficiente y la distribución diamétrica está disminuida careciendo de arbolado de mayores dimensiones?

Por todo lo anterior, es inobjetable la necesidad que tiene el estado de Chihuahua de contar con un inventario forestal, elaborado con la tecnología adecuada por personal capacitado técnicamente que trabaje en la entidad, que conozca la región y los bosques y que si resulta necesario, proponga cambios en los volúmenes de corta y establezca las medidas correctivas necesarias.

\section{PERSPECTIVAS PARA EL FUTURO}

El análisis de la situación de los bosques del estado de Chihuahua no ha sido fácil, ya que existe la información en las estadísticas y existen también experiencias personales para plantear y describir un panorama de lo ocurrido a través del tiempo en el desarrollo de las actividades realizadas sobre un recurso natural de la importancia de los bosques.

Lo difícil será predecir lo que sucederá en el futuro con relación a este mismo recurso, el cual está sometido, tanto a las fuerzas naturales que actúan sobre él, las cuales están fuera del dominio del hombre pero, al mismo tiempo, se tienen las acciones que el hombre mismo pone en práctica, las cuales quizá, sean más destructivas que la misma naturaleza, pero las que, al menos, cabe la posibilidad de que en un momento dado, pudieran ser controladas y en todo caso, utilizadas en la misma reconstrucción del recurso. Lo que se tendrá será entonces una relación de hechos que, en alguna proporción, va a incidir en el destino de los recursos forestales y se puede esperar que tales hechos tengan un efecto positivo, ya que es del dominio y demanda pública la necesidad de frenar el despilfarro o sobreexplotación de los bosques.

\section{RECOMENDACIONES}

Áreas perturbadas. La conversión de terrenos forestales a terrenos agrícolas es una práctica ampliamente ejercida en todos los países del mundo en todos los tiempos. No ha sido posible erradicarla ni en Chihuahua ni el resto del país. La necesidad de utilizar dichos terrenos es evidente, puesto que los productos cosechados anualmente, son la fuente de la alimentación de la población serrana. Sin embargo, la justificación para la existencia de tales tierras sería, en todo caso, que debieran ser permanentemente trabajadas y no, como se practica actualmente, que son tierras que se trabajan uno o dos años y se abandonan para después buscar otras, en las cuales, durante su proceso de conversión a tierras agrícolas, se destruye el arbolado y/o la vegetación existente. Esta práctica se conoce comúnmente como la "milpa que camina" (Fig. 2). Para "limpiar" de estas tierras, en la mayoría de los casos se hace uso del fuego, lo cual adiciona un elemento más de destrucción.

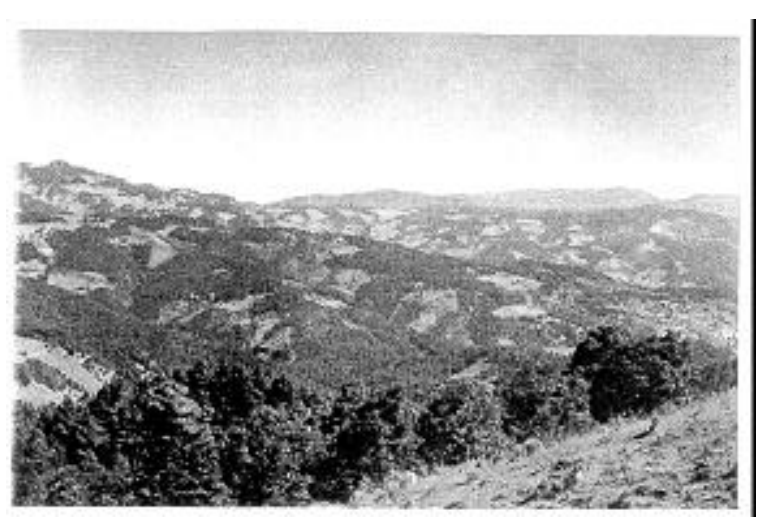

Figura 2. Ejemplo de "milpa que camina" devorando bosques.

Como se mencionó en párrafos anteriores, en el inventario de 1962, se definieron 700000 ha de áreas perturbadas $y$ en el de 1992-94 fueron 768000 ha; esto es, un avance persistente de destrucción forestal de 68000 ha, lo que representa un 
promedio de 1943 ha/año, sólo para el estado de Chihuahua. El total de ellas que corresponde a 768000 ha, es una superficie considerable con un potencial económico extraordinario si pudieran entrar en un programa de rehabilitación agrícola. El uso de cultivos apropiados para cada región, con semillas genéticamente mejoradas, con fechas apropiadas de siembra, uso adecuado de fertilizantes e insecticidas, etc. son recursos técnicos del dominio total de expertos agrícolas que, una vez puestos al servicio de los propietarios -ejidos, comunidades 0 particulares- pudieran revertir la lamentable condición de terrenos abandonados en un franco proceso de erosión, a fuentes permanentes de producción.

Pudiera darse el caso también de que, por tratarse de terrenos de vocación eminentemente forestal, se decidiera y planeara su reincorporación al cultivo natural o sea el bosque. Para eso habría que diseñar un intenso y completo programa de reforestación, el cual no sería de ninguna manera algo extraordinario, ya que en diversos países con similares problemas de deforestación, se han registrado exitosos programas de reforestación.

A este respecto, Zimmermann (1957) afirma: "Hablando en general, la mayoría de los países industriales han pasado por tres etapas en su historia forestal. La primera se caracteriza por una explotación enérgica y con frecuencia despiadada de sus propios bosques vírgenes. Ésta es seguida, generalmente, por un período en que se depende en proporción cada vez mayor del abastecimiento procedente del extranjero. Cuando la importación de productos forestales se convierte en una carga financiera demasiado pesada, se inicia, en muchos casos, el tercer capítulo, un esfuerzo para restaurar parcialmente los recursos forestales domésticos".

Con relación a lo anterior y conforme a la situación actual de nuestros bosques y nuestra industria forestal, todo hace indicar que es tiempo de iniciar la tercera etapa que es la restauración de estos bosques (Fig. 3).

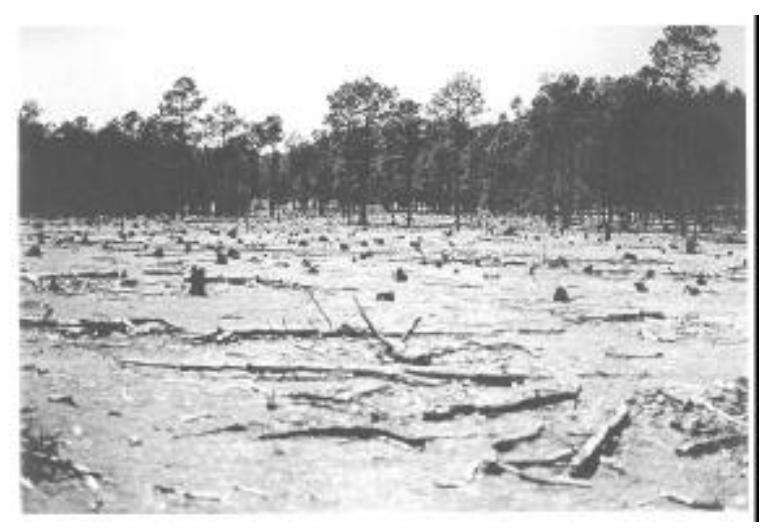

Figura 3. Deforestación en los bosques de Chihuahua.

Dada la magnitud del problema que encierra no sólo el derroche de los bosques del estado, causado por el exceso de volúmenes extraídos, sino a la degradación, cada vez más notable del ambiente y de los demás recursos asociados, se tendrá un cambio radical en cuanto al tratamiento que los niveles gubernamentales habrán de darle a este progresivo y creciente problema. Se deberá contar para lograrlo con la decidida voluntad política de las autoridades correspondientes y sobre todo, con los recursos económicos suficientes para iniciar y darle continuidad a los trabajos.

Para lograr tal efecto se deberán definir las áreas a restaurar, ya identificadas en cuanto a su superficie y ubicación geográfica. Dependiendo de los recursos que se puedan canalizar a estos trabajos, se podrán seleccionar y programar la extensión de los terrenos por reforestar anualmente, entendiendo que lo que se tendrá que hacer, en primera instancia, es detener la apertura de nuevas tierras dentro de los bosques.

Semillas. Para cualquier programa de reforestación es necesario contar con semillas de las especies que se planee establecer las que, de antemano, deberán provenir de las especies existentes en el área actualmente. Dadas las características 
de la coníferas, de producir semillas en cantidades más o menos regulares en ciclos de 5 ó 6 años, será necesario planear y realizar cosechas precisamente en tales años, en cantidades suficientes para cubrir programas de producción de plantas para este período. Las técnicas de producción de semillas indican la necesidad de escoger los "árboles padres", aquellos individuos maduros con la mejor conformación física, sanos, los de mayor altura, libres de enfermedades y provistos de una copa de forma regular y bien distribuida (Fig. 4).

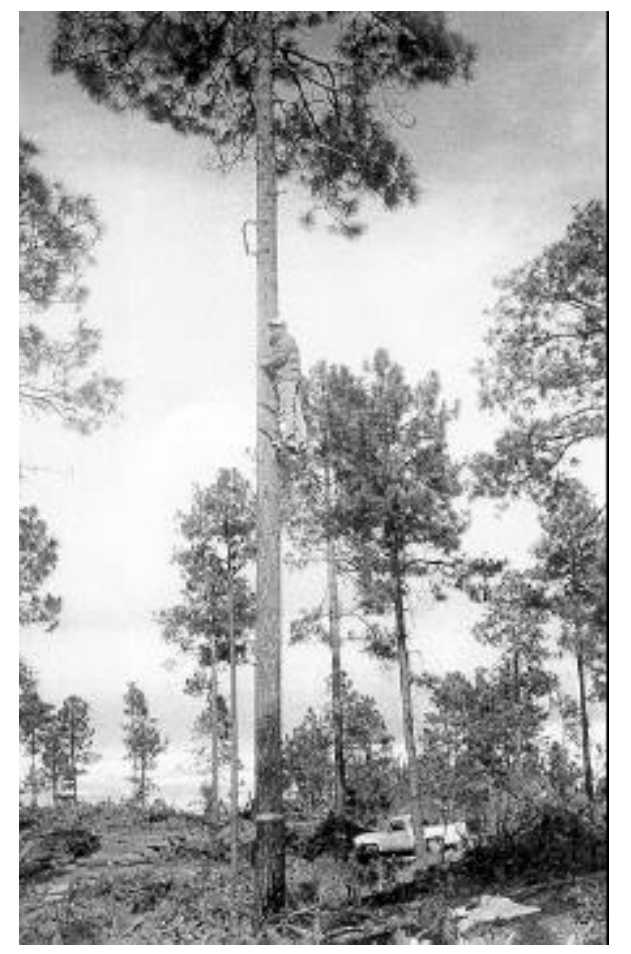

Figura 4. Ejemplar de árboles padres

Las semillas de las coníferas tienen la propiedad de poder almacenarse por períodos de hasta 10 años o más, en cámaras frías, sin perder sus propiedades de germinación, lo cual es importante si se toma en cuenta los periodos irregulares de producción de éstas. En el estado de Chihuahua se han hecho intentos y a la fecha existen algunas "áreas semilleras", las cuales necesitan incrementarse hasta lograr el número necesario para producir semillas suficientes para reforestar grandes áreas. Se ha mencionado ya la existencia de alrededor de 760000 ha de bosques que fueron desmontadas para cultivos agrícolas. Suponiendo un programa de reforestación de alrededor de 5000 ha por año, sería necesario producir alrededor de 5 millones de plántulas para ser sembradas con una densidad de 1000 plantas/ha. Sí el ciclo de recolección de semilla puede ser de 5 ó 6 años, sería necesario recolectar ceca de 25 millones de semillas, cantidad que no es fácil de alcanzar.

Las 5000 ha que se estima es necesario reforestar anualmente representan la realización de un trabajo de grandes dimensiones, que requeriría de una organización técnica y administrativa así como de mantener la superficie por reforestar en forma constante. Así que se necesitarían alrededor de 50 años para reforestar 250000 ha, que significan apenas la tercera parte del total de la superficie que actualmente se encuentra deforestada. Así de grave es el problema.

Viveros. Los programas masivos de reforestación aunados a climas extremosos como los del estado de Chihuahua, requieren de instalaciones tipo invernadero para la producción de árboles. Estos invernaderos debe estar provistos de temperatura controlada durante todo el año además de sistemas de riego y fertilización automáticos, para permitir a las plántulas un desarrollo más rápido y sano. En el estado se cuenta con experiencias en este tipo de actividades y no sería problemático la producción a gran escala en forma permanente de millones de plántulas.

Finalmente, se debe asegurar que se mantendrá una política forestal más congruente con la realidad que viven los bosques, no sólo de esta entidad sino de todo el país y que se buscará coordinar mejor los esfuerzos en todas las áreas forestales. Se han centralizado ya estas actividades en una sola dependencia del Ejecutivo, a partir del año 2001 la responsabilidad del manejo de los bosques es función del Consejo Nacional Forestal (CONAFOR, 2001). 


\section{CONCLUSIONES:}

- La gran extensión de los bosques del Estado de Chihuahua, representa un renglón económico de gran importancia además de un enorme significado social.

- No obstante que se han levantado tres inventarios forestales en este Estado, sus resultados son confusos y no permiten definir los cambios sufridos en la vegetación en los tiempos en que dichos inventarios se realizaron (1962-1994).

- Las estadísticas oficiales relativas a los permisos autorizados para el corte de madera, dejan claro la que no es posible la corta de dichos volúmenes, surgiendo la duda de que quizá la capacidad de los bosques ya no puede ofrecer tal cantidad de madera.

- La superficie perturbada en los bosques del estado, presenta una tendencia alcista, lo que significa una destrucción permanente de el recurso bosques y sus servicios ambientales.

- La actividad económica se ha concentrado principalmente en la extracción de madera y los bosques no se han manejado bajo el concepto actual del uso múltiple a fin de permitir que los dueños y poseedores logren mayores beneficios a partir de ellos.

- Los bosques del estado de Chihuahua, captan y controlan el escurrimiento de las aguas de Iluvia, que surten a otros estados vecinos que pagan por ella, sin que, ni el gobierno estatal ni los propietarios de los bosques, reciban remuneración alguna, al menos para proteger los cauces en contra de procesos de erosión y así permitir que los escurrimientos se mantengan y estén libre de sedimentos.

- El dueño de un bosque que no posea una industria con la que pueda transformar su materia prima y darle un valor agregado, nunca podrá obtener suficientes beneficios que le permitan cuidarlo y manejarlo en forma permanente. Al mismo tiempo, una industria que carezca de bosques que lo abastezcan continuamente, no podrá planear su competitividad ni asegurar su permanencia en el mercado.

- El estado de Chihuahua es aún rico en recursos forestales, los cuales debe cuidar sobre la base de un manejo forestal inteligente y sobre todo el bajo el concepto de USO MÚLTIPLE DEL BOSQUE que es, en última instancia, la manera más completa de llevar a cabo su utilización.

- El gobierno del estado de acuerdo con la Legislación existente, puede solicitar la responsabilidad del manejo directo y la administración de sus propios bosques.

\section{RECOMENDACIONES}

- Que el gobierno del estado gestione la elaboración del inventario forestal de toda la entidad.

- Que se calculen los ingresos que recibe la Federación por concepto de la venta de agua a los agricultores, tanto del estado de Chihuahua, como de los de Sonora y Sinaloa y se solicite una partida especial para cuidar y conservar las cuencas hidrográficas del Estado.

- Que se busquen formas de asociación entre los dueños y poseedores de bosques y de los propietarios de las industrias establecidas con el fin de garantizar mejores perspectivas a los primeros y abastecimiento permanente a los segundos, amén de buscar una mayor protección al recurso, incluyendo programas turísticos.

- Que se inicie un proceso de recuperación de áreas degradadas con base en trabajos de reforestación 
y/o cultivos agrícolas técnicamente planeados.

- Que el Gobierno estatal gestione la administración total de los bosques de la entidad con todos los recursos asociados que son directamente dependientes y promover o instaurar en ellos el concepto del uso múltiple.

- Que los servicios técnicos forestales que han venido manejando los bosques se integren en forma obligatoria con técnicos especialistas en agricultura, ganadería, fruticultura y manejo de cuencas y no que sean responsables únicamente de la extracción de madera.

\section{BIBLIOGRAFÍA CONSULTADA}

Cámara Nacional de la Industria Forestal. Varios años. Memoria Económica

Comisión Nacional Forestal (CONAFOR). 2001. Decreto de Creación. conafor. gob.mx/pinfgen.htm.

Instituto Nacional de Geografía y Estadística (INEGI). 1970. Censo de población 1970.

Juárez T., P. y M. Pando O. 1993. Diagnóstico de la industria de aserrío en Chihuahua. Folleto Técnico No. 2. SARH/INIFAP. CEDIR Campo Experimental Madera.37 p.

Meadows, D.H., D.L. Meadows y J. Randers. 1992. Beyond the limits. Chelsea Green 300 p.

Ruelas M., L. y R. Dávalos S. 1999. La industria forestal del estado de Chihuahua. Madera y Bosques 5(2):79-91.

Secretaria de Agricultura y Recursos Hidráulicos (SARH). 1991. Inventario Nacional Forestal de Gran Visión19911992. Subsecretaría Forestal y de la Fauna.

Secretaria de Agricultura y Recursos Hidráulicos (SARH). 1994. Inventario Nacional Forestal Periódico 19921994. Subsecretaría Forestal y de la Fauna Sllvestre. $81 p$

Secretaria de Medio Ambiente, Recursos Naturales y Pesca (SEMARNAP). 1997. Ley Forestal y su reglamento. México, D.F. 168 p.

Zimmermann, E. W. 1957. Recursos e industrias del mundo. Fondo de Cultura Económica. México, D.F.»

1 Consultor Forestal. Av. San Felipe 101. Col. San Felipe. Chihuahua, Chih.

Manuscrito recibido el 30 de Julio de 2001

Aceptado 10 de marzo de 2002

Este documento se debe citar como:

Escárpita, H., A. 2002. Situación actual de los bosques de Chihuahua. Madera y Bosques 8(1):3-17. 